\title{
Design and trial-produce of a special nail-tooth thresher for pulses crops
}

\author{
Xianfei Xia, Qiaomin Chen*, Hongru Xiao and Guang Yang \\ Nanjing Research Institute for Agricultural Mechanization, Ministry of Agriculture, Nanjing 210014, China.
}

\begin{abstract}
Pulses crops are widely distributed in China, but mechanization production-level of this crops is relatively low at present. So, a special nail-tooth thresher for pulses crops was carried out in this project to solve the problem of mechanical threshing. The roller diameter, speed, length, and nail-tooth structure, stripper concave screen, power device and cleaning system are determined by detailed theoretical calculation. Testing result of the trial-production prototype showed that the threshing roller with large diameter and low rotating speed, the nail-tooth threshing mechanism and the concave plate screen with large spacing are suitable for the broad bean thresher. The optimal combination is roller speed $400 / \mathrm{min}$, feed quantity $1.2 \mathrm{~kg} / \mathrm{s}$ and concave tolerance $54 \mathrm{~mm}$. Testing results showed that impurity content and breaking rate of the developed nail-tooth type broad bean thresher were respectively $1.09 \%$ and $3.45 \%$, It could improve the efficiency of the pulses crops threshing process significantly.
\end{abstract}

\section{Introduction}

Pulses crops are widely distributed in China, there are more than 20 kinds that have been cultivated, and the main varieties are mung bean, adzuki bean, broad bean, pea and kidney bean. The pulses crops have the function of improving the conditions of soil nutrient and feeding for draught animals. It is an ideal crop for grain-legume rotation and organic dry farming, and has important significance for the sustainable development of agriculture. Broad bean is a representative variety of pulses crops.

Broad bean, also known as Buddha bean, LuoHan bean, orchid bean and so on. With a protein content of about $30 \%$, broad bean is nutritious and widely used. It is one of the important legume crops in the world, and broad bean is mainly distributed in northwest, southwest and Yangtze River Delta areas in China. The planting area is about 800,000 hectares (12 million $\mathrm{mu}$ ), and the total annual production is over 1.6 million tons.

However, mechanization production-level of the broad bean is relatively low at present, and most of them are completed by artificial harvesting (or pod picking), threshing and cleaning. The operation intensity is large and the production cost is high. For the traditional corn or rice thresher, its threshing operations primarily through the installation of the tooth with high-speed rotation on the spindle, is not suitable for pulses crops. So, the demand for mechanized harvesting equipment is very urgent. Due to the large grain size and high straw specific gravity, broad bean is easily broken during mechanical threshing, and the impurities are hard to clean. Therefore, performance requirements of the machine are relatively high [1-3]. In this context, the design and development of

Corresponding author: dire-chen@foxmail.com broad bean thresher was carried out in this project to solve the problem of mechanical threshing in the broad bean harvesting process.

\section{Design of the main components}

Design parameters of the main components include roller diameter, roller speed, nail-tooth structure, length of the roller, stripper concave screen, power device and cleaning system. They are determined by the following methods.

\subsection{Roller diameter}

Diameter of the roller has an important influence on threshing effect, when the diameter is too small, straw is easily entangled and the separation area of the concave plate is also directly reduced. Large diameter threshing roller can effectively increase the threshing and separating time of ears, and improve the threshing and separating ability and production efficiency. At present, the commonly used diameter of rice and wheat threshing machines is $450 \sim 650 \mathrm{~mm}$, then roller diameter of the threshing machine studied in this paper is selected as $400 \mathrm{~mm}$ through comprehensive analysis [4].

\subsection{Roller speed}

The nail-tooth threshing mechanism realizes the separation of grains and stalks by the action of the hammer [5-9], line speed range at the end of the nail is usually $7 \sim 13 \mathrm{~m} / \mathrm{s}$. However, due to the large grain size of broad bean, the linear speed of roller cannot be too high, otherwise it is easy to damage broad bean in the threshing process. While the operation efficiency will be affected if 
it is too low. Therefore, $9 \mathrm{~m} / \mathrm{s}$ is selected. So, according to formula 1 , the speed of roller is $429.93 \mathrm{r} / \mathrm{min}$.

$$
n=\frac{60 v}{\pi D}
$$

Where, $D$ is the diameter $(\mathrm{mm})$ of the roller; $v$ is the linear speed $(\mathrm{m} / \mathrm{s})$ of the nail-tooth.

\subsection{Nail-tooth structure}

The number and arrangement of the nail-tooth has a direct influence on the threshing performance indicators of un-threshing, entrainment loss and broken grain rate. It determines the work quality and productivity of the machine [10].

Design of the nail teeth is arranged evenly in 4 rows and fixed on the roller, the nail tooth height is $66 \mathrm{~mm}$, diameter is $12 \mathrm{~mm}$, tooth distance is $100 \mathrm{~mm}$ and the number of teeth is 40 in this project. In addition, the rubber layer is covered on the teeth to reduce grain broken. When the broad bean straw enters the threshing chamber through the hopper, the nail teeth rotate and agitate the broad bean straw. On the one hand, the roller has a tangential strike force along the cylinder circumference, on the other hand, it has a right thrust along the axial direction, forcing the material to move toward the discharge port.

\subsection{Length of the roller}

The length of roller threshing section is an important parameter affecting threshing quality, if the roller is too short, the net removal rate will be affected. While the roller is too long, it will increase the manufacturing cost and the size of the threshing machine. The length of roller is calculated as follows.

$$
L=a\left(\frac{Z}{K}-1\right)+2 \Delta L
$$

Where, $a$ is the distance between teeth; $Z$ is the total number of teeth; $K$ is the number of teeth rows; $\triangle L$ is the distance from the nail teeth to the end of the tooth rod, generally $15-25 \mathrm{~mm}$.

The length of the roller is $950 \mathrm{~mm}$ calculated by equation 2 .

\subsection{Stripper concave screen}

In the threshing process, the concave plate can well isolate the straw, and at the same time, the screen holes distributed on the concave plate can make the shedding broad bean seeds leak to the clear screen $[11,12]$.

There are two main types of concave structure: grid and punch, and the grid concave has great strength, good rigidity, large sieve hole and good threshing and separating effect. The threshing process of broad bean is mainly completed in the front part of the roller, and the latter part is mainly used for separating and threshing, so the grid form threshing concave plate is adopted.

The screening efficiency of concave screen depends mainly on the length and effective separation area of the concave plate. In a certain range, screening efficiency will increase with the length of the concave screen. At the same time, the larger hole ratio of concave plate screen, the higher screen efficiency of concave screen. The hole ratio of concave plate screen $\mathrm{A}$ is calculated by equation 3 . The hole ratio of concave plate scree of the machine developed in this paper is $72 \%$.

$$
A=\frac{a_{l} b}{r \pi L} \times 100 \%
$$

Where, $A$ is the hole ratio of concave plate scree, $a_{1}$ is the number of sieve holes, $b$ is the area of sieve hole, $r$ is the roller radius, $L$ is the roller length.

\subsection{Power device}

The thresher shall be equipped with motor to provide threshing power, screening power and cleaning fan power. Combined with the structure design and practical application of the thresher, the matching motor with 5.5 $\mathrm{kW}$ power is selected under the condition that the threshing capacity is $3 \mathrm{t} / \mathrm{h}$ and the thresher works normally.

\subsection{Cleaning system}

From feeding broad bean material into the threshing section, to obtaining clean bean seeds, a large amount of straw, dust and sundries mixed with materials should be cleaned by the cleaning system. The separation principle is as follows: the fallen bean seeds and small impurities fall through the grid concave hole, during the falling process, the fine impurities are sucked into the fan by the negative pressure fan and discharged from the fan outlet while the grains fall into collection box with the action of reciprocating vibrating screen.

\section{Entire design and test verification}

The entire design was developed by integrating the above design parameters as shown in Figure 1, then the prototype production was carried out. In order to verify the working performance, the full-scale experiment was finished and the key operating parameters were tested. The operating principle and testing methods of impurity rate and breaking rate are as follows.

\subsection{Operating principle}

The naturally dried straw after cutting was sent into threshing machine from feeding mouth, motor drive the roller to rotate at a certain speed, then the fast-moving nail keep hitting the straw in the threshing chamber to achieve the rapid separation of grains and straws. Next, grain entered the cleaning system through sieve mesh gap, and the remained straw was discharged out of the machine through crushing device. The clean grain can be obtained at the discharge port.

The main indexes to evaluate threshing machine operation performance include breaking rate and impurity rate. 


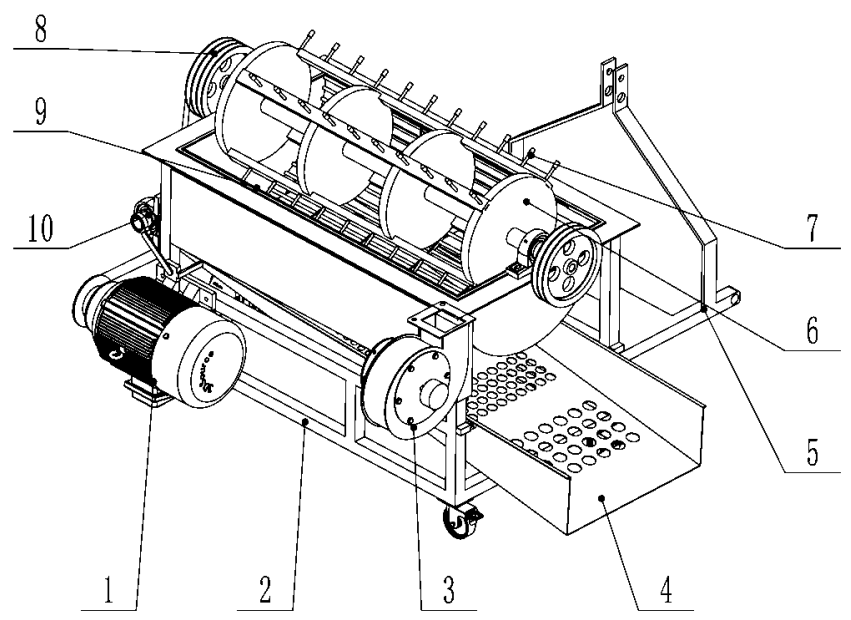

1-motor, 2-frame, 3-cleaning fan, 4-grading screen, 5-suspension frame, 6-threshing roller, 7-nail-tooth, 8-driving wheel, 9-gravure screen, 10-vibration mechanism

Figure 1. The overall structure diagram of broad bean threshing machine.

\subsection{Breaking rate}

According to the standard requirements, a random sample of broad bean no less than $2000 \mathrm{~g}$ was collected and the seeds with injuries and obvious cracks were selected out and weighted. The breaking rate is calculated according to equation (4).

$$
Z_{S}=\frac{W_{S}}{W_{\mathrm{i}}} \times 100 \%
$$

Where, $Z_{s}$ is grain breaking rate, $\%$. $W_{s}$ is the mass of broken grains, g; $W_{i}$ is the total grain mass of the sample, g.

\subsection{Impurity rate}

After each testing, 2,000g of broad beam seeds were collected from the outlet. Impurities and grains were separated and weighed separately. The impurity rate is calculated according to equation (5).

$$
S_{W}=\frac{W_{w}}{W_{z}} \times 100 \%
$$

Where, $S_{W}$ is grain impurity rate, $\% . W_{w}$ is the mass of impurity, $\mathrm{g} ; W_{z}$ is the total mass of the sample, $\mathrm{g}$.

\subsection{Experimental design}

The controllable conditions in the experiment are feed quantity, concave tolerance and roller speed. The range of each testing variables is shown in Table 1. Different experiments are arranged by the orthogonal experiment design method. The experiment is adopted $L_{9}\left(3^{4}\right)$ orthogonal tables to repeat 3 times. The correlation of variables is analyzed and the optimized parameter combinations were obtained.
Table 1. Experimental factors and levels.

\begin{tabular}{|c|c|c|c|}
\hline Levels & $\begin{array}{c}\text { Roller speed } \\
\mathrm{r} / \mathrm{min}\end{array}$ & $\begin{array}{c}\text { Feed } \\
\text { quantity } \\
\mathrm{kg} / \mathrm{s}\end{array}$ & $\begin{array}{c}\text { Concave } \\
\text { tolerance } \\
\mathrm{mm}\end{array}$ \\
\hline 1 & 400 & 0.75 & 50 \\
\hline 2 & 450 & 1.00 & 54 \\
\hline 3 & 500 & 1.25 & 58 \\
\hline
\end{tabular}

\subsection{Testing result}

According to the above methods, threshing performance of the prototype was tested. Variety of the testing broad bean was Qidou 2, and moisture content of the bean straw was $12 \%-16 \%$. Testing results was shown in Table 2, Range analysis of the experimental results was shown in Table 3.

Through range and variance analysis, we found that each factor has different effects on the variables, the roller speed has the greatest impact on the breaking rate and. The primary and secondary sequence of the factors affecting breaking rate is roller speed $>$ feed quantity $>$ concave tolerance, while the optimal combination is roller speed $400 / \mathrm{min}$, feed quantity $1 \mathrm{~kg} / \mathrm{s}$ and concave tolerance $54 \mathrm{~mm}$. In addition, the concave tolerance has the greatest impact on the impurity rate and. The primary and secondary sequence of the factors affecting breaking rate is concave tolerance $>$ roller speed $>$ feed quantity, while the optimal combination is roller speed $400 / \mathrm{min}$, feed quantity $1.25 \mathrm{~kg} / \mathrm{s}$ and concave tolerance $54 \mathrm{~mm}$.

It can be found that the optimal combinations are significantly different when a certain optimization 
variable is chosen. After weighing the influence of impurity rate and breaking rate on the result, the final optimal combination is roller speed $400 / \mathrm{min}$, feed quantity $1.2 \mathrm{~kg} / \mathrm{s}$ and concave tolerance $54 \mathrm{~mm}$. Testing results under this combination showed that impurity content and breaking rate were $1.09 \%$ and $3.45 \%$ respectively, which met the requirements of application. The threshing effect of the machine is shown in Figure 2.

Table 2. The orthogonal experiment arrangement and results

\begin{tabular}{|c|c|c|c|c|c|}
\hline \multirow{2}{*}{$\begin{array}{c}\text { Experi } \\
\text { ment } \\
\text { No. }\end{array}$} & \multicolumn{3}{|c|}{ Experiment factors } & \multicolumn{2}{|c|}{ Result } \\
\hline & $\begin{array}{c}\text { Roller } \\
\text { speed } \\
(\mathrm{r} / \mathrm{min} \\
)\end{array}$ & $\begin{array}{c}\text { Feed } \\
\text { quantity } \\
(\mathrm{kg} / \mathrm{s})\end{array}$ & $\begin{array}{l}\text { Concav } \\
\text { e } \\
\text { toleranc } \\
\text { e (mm) }\end{array}$ & $\begin{array}{c}\text { Breakin } \\
\text { g rate } \\
(\%)\end{array}$ & $\begin{array}{c}\text { Impur } \\
\text { ity } \\
\text { rate } \\
(\%) \\
\end{array}$ \\
\hline 1 & 1 & 1 & 1 & 3.25 & 0.5 \\
\hline 2 & 1 & 2 & 2 & 2.79 & 0.36 \\
\hline 3 & 1 & 3 & 3 & 3.27 & 0.2 \\
\hline 4 & 2 & 1 & 2 & 3.86 & 0.32 \\
\hline 5 & 2 & 2 & 3 & 3.13 & 0.47 \\
\hline 6 & 2 & 3 & 1 & 3.81 & 0.65 \\
\hline 7 & 3 & 1 & 3 & 3.91 & 0.68 \\
\hline 8 & 3 & 2 & 1 & 3.65 & 0.45 \\
\hline 9 & 3 & 3 & 2 & 3.42 & 0.31 \\
\hline
\end{tabular}

Table 3. Range analysis of the experimental results.

\begin{tabular}{|c|c|c|c|c|}
\hline \multirow{4}{*}{$\begin{array}{c}\text { Evaluating } \\
\text { index }\end{array}$} & Range & $\begin{array}{c}\text { Roller } \\
\text { speed } \\
(\mathrm{r} / \mathrm{min})\end{array}$ & $\begin{array}{c}\text { Feed } \\
\text { quantity } \\
(\mathrm{kg} / \mathrm{s})\end{array}$ & $\begin{array}{c}\text { Concave } \\
\text { tolerance } \\
(\mathrm{mm})\end{array}$ \\
\hline \multirow{2}{*}{$\begin{array}{c}\text { Breaking } \\
\text { rate }\end{array}$} & $k_{1}$ & 3.103 & 3.673 & 3.57 \\
\cline { 2 - 5 } & $k_{2}$ & 3.6 & 3.19 & 3.357 \\
\cline { 2 - 5 } & $k_{3}$ & 3.66 & 3.5 & 3.437 \\
\hline \multirow{3}{*}{$\begin{array}{c}\text { Impurity } \\
\text { rate }\end{array}$} & $k_{1}$ & 0.557 & 0.483 & 0.213 \\
\cline { 2 - 5 } & $k_{2}$ & 0.48 & 0.53 & 0.533 \\
\cline { 2 - 5 } & $k_{3}$ & 0.48 & 0.381 & 0.45 \\
\cline { 2 - 5 } & $R$ & 0.127 & 0.113 & 0.203 \\
\hline
\end{tabular}

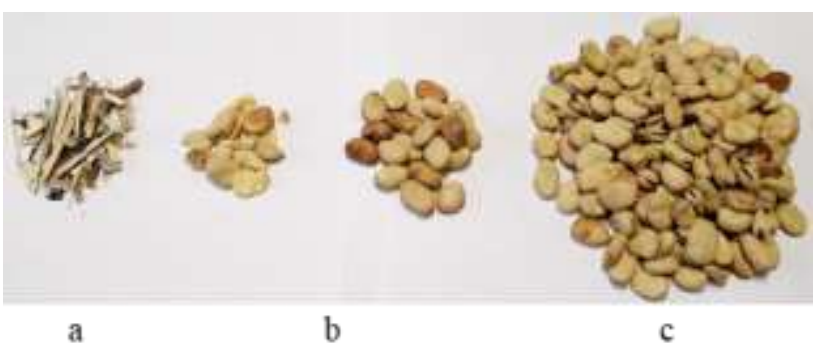

(a) impurities (b) the damaged grain (c) the ideal grain Figure 2. Threshing performance of the prototype

\section{Conclusion}

(1) In order to improve efficiency of the broad bean threshing process, the threshing roller with large diameter and low rotating speed, the nail-tooth threshing mechanism and the concave plate screen with large spacing are suitable for the broad bean thresher.

(2) The optimal combination is roller speed $400 / \mathrm{min}$, feed quantity $1.2 \mathrm{~kg} / \mathrm{s}$ and concave tolerance $54 \mathrm{~mm}$. Testing results showed that impurity content and breaking rate of the developed nail-tooth type broad bean thresher were respectively $1.09 \%$ and $3.45 \%$, achieved relatively ideal operation effect.

\section{Acknowledgments}

This work was financially supported by China Agriculture Research System (CARS-08).

\section{References}

1. Hongz $\mathrm{T}$, Bin $\mathrm{T}$, Xiaoh $\mathrm{T}$ and Ming $\mathrm{L}$, Chemicophysical properties of twenty broad bean varieties and their correlations, J. the Chinese cereals and oils association. 24 (2009) 153-157.

2. Xiaoh T, Hongz T, Bin T, Ming L, and Yangx L, Analyse physicochemical properties of broad beans in main producing areas in China, grain engineering. 17(2009) 7-11.

3. Mianc J, Dongx $X$, Yunq $G$ and Hongx R, Simplified cultivation techniques for high yield and high efficiency of faba bean in northern hebei province, agricultural science and technology newsletter. 8 (2014) 216-217.

4. Gang W, Zhuoh G, Senl M, Qing T, Chongy $\mathrm{W}$,optimization of operating parameter and structure for seed thresher device for rape combine harvester, Transactions of the CSAE. 33(2017) $52-57$.

5. Fengj $\mathrm{W}$, Hongj $\mathrm{Z}$, and Shig $\mathrm{W}$, research and development of the single-drum nail-tooth corn thresher, Journal of Qiqihar University. 31(2015) 26-29.

6. Lianx G, Shiy Z, Ruix C and Dex Y, design and experiment on soybean breeding thresher of double feeding roller and combined threshing 
cylinder, Transactions of the CSAM. 46(2015) 112-118.

7. Lianx G, Shiy Z, Ruix C and Dex Y et al, development and performance test on pneumatic cleaning-circulatory device of soybean thresher, Transactions of the CSAE.28 (2012) 22-27.

8. Lizhang X, Yaoming L, Chenghong W, et al, a combinational threshing and separating unit of combine harvester with a transverse tangential cylinder and an axial rotor, Transactions of the CSAM. 45(2014) 105-108.

9. Yaoming L, Wei Z, Lizhang X, et al, parameter test and optimization of tangential-horizontalhorizontal threshing and separating device, Transactions of the CSAM. 46(2015) 62-67.

10. Yaoming L, Tao S, Lizhang X, performance test and analysis of rape multi cylinder threshing and separating device,Transactions of the CSAE. 29 (2013) 36-43.

11. Zhifeng D, Zhongkai C, Hua $Z$ and Jin $Z$, design and experiment of rasp bar and nail tooth combined axial flow corn threshing cylinder, Transactions of the CSAE 34(2018)28 -34.

12. Zhongkai $\mathrm{C}$, Zhifeng D, Zhoujin, et al, design and research on 5TYS280 corn threshing and cleaning test bench, Journal of Agricultural Mechanization Research. 39(2017)113-117. 